\title{
REVISÃO
}

\section{A ESQUISTOSSOMOSE MANSONI EM MINAS GERAIS}

\author{
José Roberto Lambertucci1, Roberto Sena Rocha2, Omar dos Santos \\ Carvalho $^{2}$ e Naftale Katz2
}

A esquistossomose mansoni é a única esquistossomíase existente nas Américas, sendo um dos maiores problemas de saúde pública para o Brasil. Existem, segundo estimativas, 200 milhões de esquistossomóticos no mundo e cerca de 12 milhões no Brasil ${ }^{14} 29$.

Ao estudar o problema da esquistossomose no Brasil podemos considerar que, desde os seus primórdios, o ingresso e a expansão da doença foram devidos ao modelo econômico implantado; especialmente o modelo agrícola voltado para exportação, provendo o mundo de artigos, como o açúcar, de grande valor $\mathrm{e}$ consumo, já naquela época.

Com a verificação da adaptabilidade das terras do Nordeste à plantação da cana, para esta se concentrou o plantio, multiplicando-se os engenhos de açúcar. A mão-de-obra escassa, obtida do índio nativo, não era satisfatória e mais compensador foi a introdução da mão-de-obra africana, com o tráfico de escravos desde o início da colonização, mas sendo incrementado principalmente em meados do Século XVI. As estatisticas disponiveis referem que, durante todo $o$ tempo vigente da escravatura, entraram no Brasil entre 15 e 18 milhões de africanos, originários, em grande parte, de regiões endêmicas de esquistossomose, tanto mansônica quanto hematóbica. Entretanto, alguns fatores contribuiram para minimizar o perigo: a) não havia hospedeiro intermediário para o Shistosoma haematobium; e b) nem todas as regiōes brasileiras tinham condições ecológicas ou epidemiológicas propícias para o desenvolvimento dos caramujos ou para a infecção dos mesmos ${ }^{2}$.

Dessa forma houve condicionantes para que a esquistossomose se instalasse no Brasil, mas nem todas as regiōes tiveram o ingresso do parasita obrigatoriamente seguido por transmissão.

O Nordeste do pais, entretanto, com Salvador e Recife como principais portos de ingresso de escravos,

Endereço para correspondência: Dr. J.R. Lambertucci-Depto Clínica Médica - Faculdade de Medicina da Universidade Federal de Minas Gerais. 30000 Belo Horizonte, MG.

1. Núcleo de estudos sobre esquistossomose - Faculdade de Medicina da Universidade Federal de Minas Gerais.

2. Centro de Pesquisas "René Rachou"/FIOCRUZ

Este trabalho foi realizado com auxílio da FINEP e do CNPq. Recebido para publicação em 26/1/86. tinha nas terras úmidas da plantação de cana e na presença de caramujos susceptíveis as condições ideais para a transmissão. Assim, depois de certo tempo de adaptação do parasita ao hospedeiro intermediário, instalou-se a transmissão. Naquela época, devido à deficiência dos meios de transporte e à pequena mobilização da população, a área endêmica nordestina permaneceu quase inalterada por vários anos.

A dispersão da doença para Minas Gerais se fez provavelmente no início do Século XVIII com a migração em larga escala de nordestinos para a exploração do diamante e do ouro (ciclo do ouro e do diamante). A urgente necessidade de braços para as lavras levou para Minas a escravatura disponivel no Nordeste do pais, que, aliás, já estava conhecendo o declinio da produção açucareira e, por isso mesmo, prescindia de escravos. De fato, na primeira metade do Século XVIII, $60 \%$ da população era negra escrava; dos $40 \%$ restantes, dois terços eram pardos ou mulatos. Cerca de $1 / 5$ da população do Brasil, existente na época, migrou para Minas Gerais ${ }^{31}$.

Em sintese, vê-se que a esquistossomose acompanhou o homem para vários locais onde este se estabeleceu para promover o desenvolvimento do país. A maior ou menor prevalência dependeu das condições ecológicas para o caramujo, sua adaptabilidade ao esquistossoma e fatores econômicos e culturais.

\section{A esquistossomose no Brasil e em Minas Gerais}

Pirajá da Silva, em $1908^{34}$, descreve na Bahia os primeiros 20 casos de esquistossomose mansoni no país. A maioria dos estudos realizados, posteriormente, sobre a esquistossomose, tanto no que diz respeito à localização das áreas de ocorrência como no que concerne ao número de focos da doença, traçaram o mapa da endemia baseados, o primeiro na procedência dos doentes, e os outros nos resultados de inquéritos parciais e em dados fornecidos por alguns departamentos estaduais de saúde ${ }^{1} 2133$.

Davis$^{6}$, Villela 38 e Madureira Pará16, fundamentados em provas de viscerotomia, apresentaram respectivamente: $29.593,150.000$ e 267.054 exames de figados com os percentuais de 5,4, 4,0 e 2,2 para esquistossomose. No VII Congresso de Higiene reu- 
Revisão. Lambertucci JR, Rocha RS, Carvalho OS, Katz N. A esquistossomose mansoni em Minas Gerais. Revista da Sociedade Brasileira de Medicina Tropical 20: 47-52, Jan-Mar, 1987.

nido em São Paulo, em dezembro de 1948, Madureira Pará relatou 5.953 casos de esquistossomose em 420 municipios do pais ${ }^{16}$. Todavia, todos esses achados de viscerotomia se relacionavam aos locais onde os óbitos ocorreram, sem maiores indagações sobre a origem da infeç̧ão.

O inquérito publicado por Pellon \& Teixeira em 1950 e realizado em 11 estados da Federação (Maranhão, Piauí, Ceará, R. G. do Norte, Paraiba, Pernambuco, Alagoas, Sergipe, Bahia, Espirito Santo, Minas Gerais) é o mais completo, com planejamento adredemente feito, e que examinou o maior número de pessoas ${ }^{29}$. Examinaram-se, no período de 3 anos, todas as cidades e localidades com mais de 1.500 habitantes nos 11 estados estudados. A população examinada compreendeu em sua maioria crianças na faixa etária de 7 a 14 anos. $O$ método empregado no exame das fezes foi o de sedimentação espontânea ${ }^{915}$. Foram realizados 440.786 exames, obtendo-se uma prevalência de $10 \%$ para o Brasil.

No Estado de Minas Gerais examinaram-se 279 localidades, com um total de 162.491 exames parasitológicos de fezes, o que representava $66 \%$ de 245.441 escolares existentes na área das localidades em apreco. Nessas coproscopias foram diagnosticados 7.997 casos de esquistossomose, fornecendo para este Estado um percentual de 4,9 , ou um total de 400.100 esquistossomóticos 29 .

No Estado havia 167 localidades com exames positivos e 79 com percentuais superiores a $4 \%$. Foi na área da vasta zona do Mucuri onde se encontraram os maiores índices de infecção esquistossomótica: Itaipé $(74,7 \%)$, Rubim $(68,1 \%)$, Medina $(65,6 \%)$, Pedra Azul $(62,3 \%)$ e Novo Cruzeiro $(63,9 \%)^{29}$.

Os afluentes do rio São Francisco alimentam, nas localidades marginais, outros grandes focos ao norte. Na chamada Zona do Alto-Médio São Francisco se destacaram São João da Ponte $(69,2 \%)$, Coração de Jesus $(56,4 \%)$ e Fernão Dias $(56,1 \%)$. Também infectados, como núcleos de população mais condensados, embora com menores percentuais, encontravam-se na Zona da Mata: Raul Soares, Rio Casca e Dom Silvério com indices que oscilavam entre 17 a $25 \%$. Nas Zonas do Alto Paranaiba, Oeste e Metalúrgica, a infecção, ainda que presente em numerosas localidades, era apenas moderada, atingindo seus máximos nas cidades de Arcos $(16,4 \%)$, Iguatama $(17,6 \%)$ e Pains $(38,5 \%)$.

Os autores salientaram, na Zona Metalúrgica, a cidade de Belo Horizonte com 1.819 casos de esquistossomose e um percentual de 7,14. Foi nas vizinhanças da capital que se localizaram os maiores focos da Zona Metalúrgica: Santa Luzia, Lagoa Santa e Sabará.

As Zonas Sul, do Triângulo Mineiro (com exceção de um único foco isolado em Araxá) e do
Urucuia, apresentavam prevalências despreziveis (Fig. 1).

Em seguida, Pellon $\&$ Teixeira ${ }^{30}$ apresentaram novo inquérito, desta feita realizado em áreas do pais supostamente não endêmicas, compreendendo os Estados do Rio de Janeiro, Paraná, Santa Catarina, Goiás e Mato Grosso. Os resultados revelaram ai apenas $0,08 \%$ de amostras positivas.

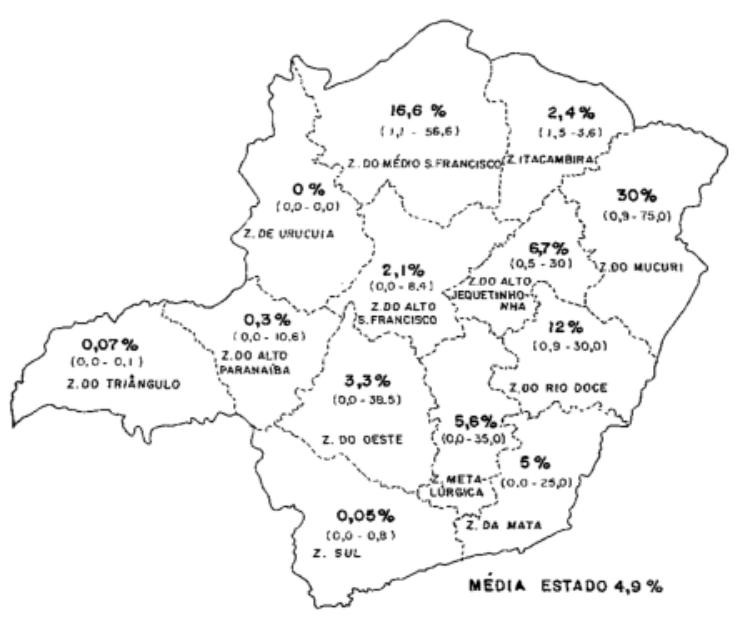

Figura 1 -Prevalência da esquistossomose no Estado de Minas Gerais, em 1950 (modificado de Pellon \& Teixeira ${ }^{29}$ )

Em 1976/77, Katz e cols ${ }^{12}$ realizaram novo inquérito coproscópico em Minas Gerais. A população examinada compreendeu escolares na faixa etária de 7 a 14 anos. Os autores utilizaram o método quantitativo de Kato modificado por Katz e cols ${ }^{11}$. $O$ total de exames programado foi de 64.940 , tendo sido examinadas 62.697 amostras qualitativamente e 61.535 quantitativamente, o que corresponde respectivamente a $96,6 \%$ e $94,8 \%$ dos exames programados. Destas últimas, havia 5.904 crianças positivas, dando uma prevalência geral de $9,6 \%$ ( $12 \%$ na zona rural e $7,2 \%$ na urbana). $O$ número provável de escolares infectados foi de 223.416 , sendo encontrada a maior prevalência na Zona do Mucuri (em torno de $20 \%$ ). Todavia, o maior número de crianças infectadas encontrava-se na Zona Metalúrgica, devido provavelmente à sua maior densidade populacional (Fig. 2).

Apesar de algumas variações regionais, a distribuição geográfica da esquistossomose no Estado de Minas Gerais não se alterou muito nos 27 anos que separam o inquérito coproscópico de Pellon \& Teixei$\mathrm{ra}^{29}$ e o de Katz e cols ${ }^{12}$. De fato, o Sul e o Triângulo Mineiro continuaram praticamente livres da endemia. Recentemente, foram relatados os primeiros casos autóctones de esquistossomose mansoni, em Itajubá, 


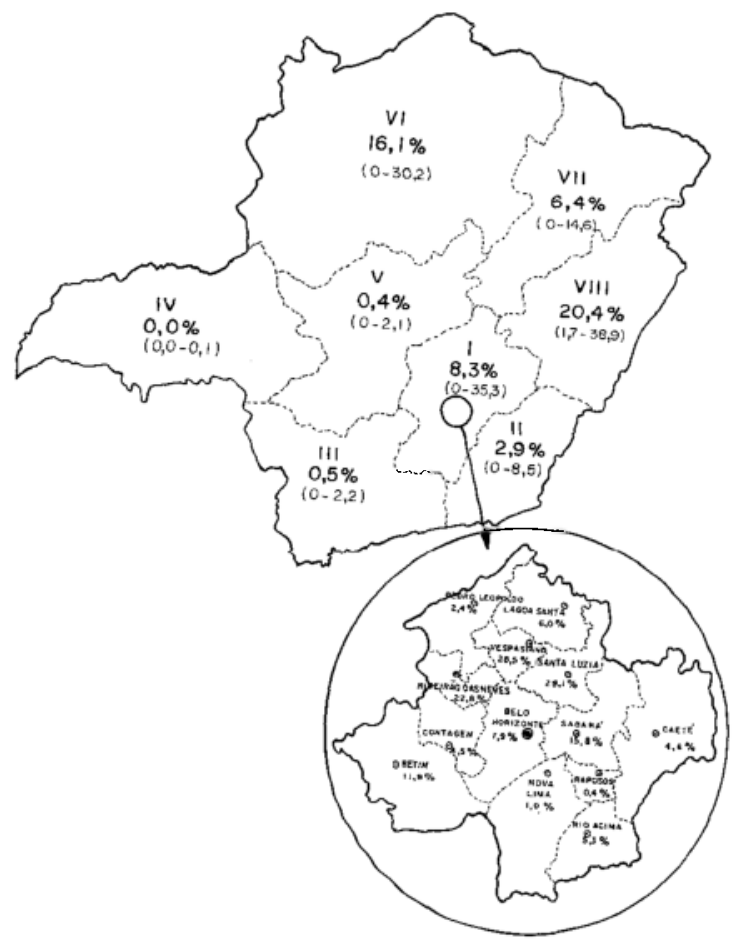

Figura 2 - Prevalência da esquistossomose por macrorregiōes em escolares no Estado de Minas Gerais, em 1978 (modificado de Katz e cols ${ }^{12}$ ).

sul do Estado de Minas Gerais ${ }^{10}$. Posteriormente a esta observação, cerca de 100 novos casos autóctones foram ali identificados (AR Santos: comunicação pessoal, 1986).

A prevalência para o Estado que era de $4,9 \% \mathrm{em}$ 1950 , entretanto, passou a $9,6 \%$ neste último inquérito (Tabela 1).

Tabela I - Estimativa do número de casos de esquistossomose no Estado de Minas Gerais em duas épocas (1950 e 1978).

\begin{tabular}{ccccc}
\hline Inquéritos & No de exames & $\begin{array}{c}\text { Exames positivos } \\
\text { No }(\%)\end{array}$ & Populąão estimada & $\begin{array}{c}N^{\circ} \\
\text { provável de } \\
\text { casos }\end{array}$ \\
\hline $\begin{array}{c}\text { Pellon \& Teixeira } \\
(1950)\end{array}$ & 162491 & $7997(4,9)$ & 8132111 & 400100 \\
$\begin{array}{c}\text { Katz e cols } \\
(1978)\end{array}$ & 61535 & $5904(9,6)$ & 12697900 & 1218998 \\
\hline
\end{tabular}

Enquanto a população de 7 a 14 anos aumentou 1,7 vezes em 25 anos, a prevalência mais que dobrou neste mesmo periodo. $\mathrm{O}$ grande preço da doença é, sem dúvida alguma, pago pela população rural. $\mathrm{Na}$ maior parte das regióes estudadas, as prevalências em zona rural foram maiores do que nas zonas urbanas, chegando em algumas regiões a ser três vezes maior.

\section{Hospedeiros intermediários do S. mansoni em} Minas Gerais

Os três principais hospedeiros intermediários do $S$. mansoni no Brasil já foram identificados no Estado de Minas Gerais. A presença de B. glabrata, $B$. tenagophila e $B$. straminea foi notificada em cerca de 140 localidades do território mineiro ${ }^{8}$ (Fig. 3).

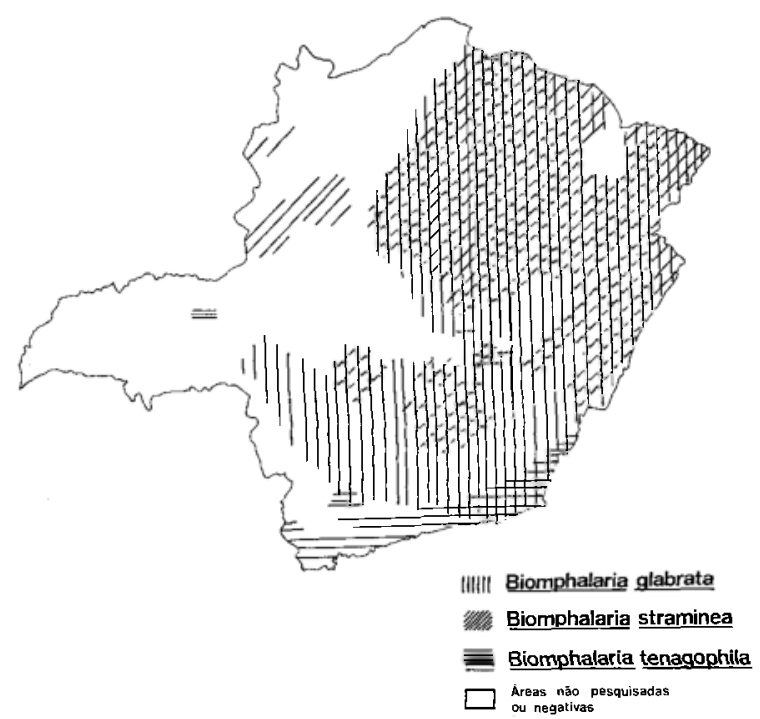

Figura 3 - Distribuição dos hospedeiros intermediários do Schistosoma mansoni, no Estado de Minas Gerais (Lobato-Paraense ${ }^{27}$ - atualizado pelos AA, 1985).

Das três principais espécies de caramujos, a $\boldsymbol{B}$. glabrata é a mais importante, não só pela amplitude de distribuição como também por sua eficiência na transmissão do $S$. mansoni, sendo responsabilizada pela quase totalidade dos focos da doença. Sua distribuição apresenta maior concentração a leste do rio São Francisco 2627.

A B. tenagophila foi encontrada em Jaboticatubas, ao norte de Belo Horizonte, e a partir dai ela está presente no centro, oeste, sul e sudeste do Estado. Só recentemente esta espécie foi observada naturalmente infectada em três localidades de Minas Gerais: Jaboticatubas $^{22}$, Itajubá 4 e Belo Horizonte ${ }^{3}$.

A terceira espécie vetora, a $B$. straminea, é a mais bem-sucedida e adaptada às variações climáticas, sendo encontrada em quase todas as bacias hidrográficas do Brasil ${ }^{32} 35$. A infecção natural desta espécie em Minas Gerais só foi observada uma única vez, na divisa dos municipios de Lagoa Santa e Pedro Leopoldo ${ }^{7} \mathrm{e}$ até $\mathrm{o}$ momento não tem importância epidemiológica.

\section{A esquistossomose em Belo Horizonte}

Os primeiros dados concretos sobre a ocorrência de casos autóctones de esquistossomose mansoni em Belo Horizonte datam de 1919, ou seja, vinte e dois anos após a inauguração da nova capital do Estado de Minas. 
Tais registros se devem a Teixeira ${ }^{36}$ que, em 9.955 exames coproscópicos, assinalara $49(0,5 \%)$ casos, 36 dos quais em crianças menores de 15 anos, na maioria, naturais da própria cidade.

Após o relato destes casos, longo tempo se passa, sem que a bibliografia especializada assinale novos estudos sobre a moléstia em Belo Horizonte, e mesmo no Estado, salvo eventuais registros e observações clínicas de casos mais ou menos isolados.

Por outro lado, é somente com a adoção de adequada técnica de exame parasitológico das fezes (método de sedimentação-concentração) ${ }^{9}{ }^{15}$, cuja utilização foi sugerida por Martins ${ }^{17}$, que o problema da doença passa a ser melhor e mais realisticamente avaliado em termos de medicina coletiva.

Em 1937, Martins ${ }^{17}$, empregando o método de sedimentação, verifica uma prevalência de $27,8 \%$ entre 180 escolares da Vila Afonso Pena (bairro rural da capital). Martins \& Versiani 19 publicam resultados de exames de fezes de pessoas que espontaneamente procuraram o Instituto Ezequiel Dias, referente ao decênio 1928-1938. Observaram aumento progressivo da prevalência: de $2,8 \%$ em 1928, para $11,7 \%$ em 1938. Os autores chamavam, no entanto, a atenção para o fato de que este aumento de indice de positividade podia ser atribuído, parcialmente, ao aperfeiçoamento das técnicas de diagnóstico, mormente à introdução do método de concentração de ovos por sedimentação, como também ao aparecimento de um novo e importante foco de disseminação criado pelo próprio homem.

De fato, ao que parece, a rápida e ampla disseminação da doença em Belo Horizonte, a partir de 1937/38, se deveu em boa parte à utilização da então recém-construída Lagoa da Pampulha, largamente utilizada para a prática de vários esportes: natação, remo, etc., havendo sido mesmo comprovada a infecção autóctone de cerca de $70 \%$ de casos entre 145 banhistas que utilizaram a Lagoa e que, anteriormente, não revelavam ovos de $S$. mansoni em exames coproscópicos $^{20}$.

Versiani, Martins \& Pena Sobrinho ${ }^{37}$, em 1945 , realizaram inquérito coproscópico em 24 escolas primárias da capital. Em 2.352 amostras examinadas, encontraram 294 positivas (12,5\%). Como já vimos anteriormente, no inquérito de Pellon \& Teixeira ${ }^{29}$ de 25.210 crianças examinadas, $1.819(7,1 \%)$ tinham esquistossomose mansoni. Estes dados foram confirmados por Cotta \& Milward de Andrade 5 para um total de 28.707 exames coproscópicos, executados de 1957 a 1964, a prevalência foi da ordem de $7,4 \%$ ( 2.136 casos). Mais recentemente, Katz e cols ${ }^{12}$ voltaram a encontrar dados semelhantes; de $\mathbf{2 1 . 9 9 0}$ exames realizados, 1.735 foram positivos para o $S$. mansoni, com prevalência de $7,9 \%$.
A distribuição de caramujos em Belo Horizonte é ampla. A espécie predominante é a B. glabrata e a população mais exposta ao contágio encontra-se na zona norte da cidade, devido às condições epidemiológicas locais.

Os últimos inquéritos 51228 , realizados em Belo Horizonte, estão a sugerir uma estabilização na prevalência da doença em Belo Horizonte, em números relativos, já que a população aumentou muito neste periodo. Este achado provavelmente se explica pela urbanização de grandes áreas da cidade, com tendência a deslocar a transmissão da doença para os núcleos populacionais da periferia da região metropolitana. De fato, se nos bairros centrais da cidade há desaparecimento dos antigos focos, nos mais recentemente criados a doença se apresenta com caráter nitidamente expansionista 13 .

\section{A Lagoa da Pampulha}

A história da esquistossomose em Belo Horizonte está intimamente relacionada com a bacia hidrográfica da Lagoa da Pampulha, ainda que os primeiros casos autóctones desta parasitose tivessem sido diagnosticados em 1919, ou seja, 17 anos antes do início da construção da barragem, que daria origem à Lagoa, em 1936. Todavia, segundo Martins \& Versiani $^{19}$, foi após a criação desta Lagoa que o número de portadores de $S$. mansoni começou a aumentar extraordinariamente na capital mineira.

$O$ primeiro relato sobre a ocorrência de planorbídeos hospedeiros do $S$. mansoni no interior da Lagoa foi feito por Martins \& Versiani ${ }^{20}$, em 1938. Naquela ocasião foram coletados "numa extensão de cerca de $\mathbf{4 0 0}$ metros", 42 exemplares de $B$. glabrata, sendo que um $(2,4 \%)$ eliminava cercárias de $S$. mansoni.

Colocada a par do problema, a prefeitura de Belo Horizonte, entre outras medidas, determinou o esvaziamento temporário daquela coleção hídrica ${ }^{24}$. Naquela oportunidade, relatam Martins \& Versiani ${ }^{19}$, "fizemos um cálculo grosseiro da quantidade de "Planorbis" ali existente, tomando por base o seu número médio por metro quadrado e a área abrangida pela represa: verificamos que chegavam a 12 ou 15 milhões aproximadamente".

Em 1940/41, Martins, citado por Milward de Andrade ${ }^{23}$, realizando uma "inspecção sumária" na Lagoa verificou que o número de planorbídeos era bastante reduzido. Cerca de 11 anos mais tarde, Martins e $\mathrm{Falcão}^{18}$ capturaram, naquela coleção hídrica, 176 exemplares de $B$. glabrata, dos quais um $(0,6 \%)$ eliminava cercárias de $S$. mansoni.

Revendo a literatura sobre a ocorrência de hospedeiros intermediários do S. mansoni, no interior 
Revisão. Lambertucci JR, Rocha RS, Carvalho OS, Katz N. A esquistossomose mansoni em Minas Gerais. Revista da Sociedade Brasileira de Medicina Tropical 20: 47-52, Jan-Mar, 1987.

da Lagoa da Pampulha, verifica-se que após a inauguração da atual barragem em janeiro de 1958 , até abril de 1981, a população de planorbídeos dentro da Lagoa manteve-se escassa, não sendo descrito nenhum exemplar parasitado pelo $S$. mansoni.

Por esse motivo, acredita-se que hoje a Lagoa da Pampulha tenha pouca importância na transmissão da esquistossomose em Belo Horizonte. $\mathrm{O}$ mesmo, entretanto, não é verdadeiro para os seus afluentes. A Lagoa é resultante do represamento de sete córregos (Mergulhão, Bento Pires, Ressaca, Zoológico, Braúnas, AABB e Olhos D'Água) e nestes tem sido freqüente o encontro do hospedeiro intermediário eliminando cercárias de S.mansoni ${ }^{35}$. Este achado é reforçado pela demonstração do alto índice de infecção por $S$. mansoni nos escolares da região, relatado no inquérito coproscópico realizado por Katz e cols ${ }^{12}$, em 1978.

Em 1972, Milward de Andrade 25 relata pela primeira vez a existência de $B$. tenagophila na Lagoa da Pampulha.

O encontro, mais recentemente, de quatro exemplares de planorbídeos parasitados por $S$. mansoni (dois $B$. glabrata e dois $B$. tenagophila $)^{3}$ e a dispersão atual desta última espécie, por todo o perímetro lacustre, traduzem a mais importante alteração ocorrida nos últimos 30 anos, na história natural da esquistossomose mansoni na Lagoa da Pampulha. A constatação destes fatos deve merecer atenção especial das autoridades responsáveis, face a relatos recentes de exemplares de $B$. tenagophila infectados, em duas cidades do Estado de Minas Gerais: Jaboticatubas ${ }^{22}$ e Itajubá4.

\section{Conclusões}

A prevalência da esquistossomose vem aumentando no Estado de Minas Gerais e atingindo regiões anteriormente indenes (sul de Minas).

Em Belo Horizonte a prevalência se mantém estável, às custas de uma diminuição do número de casos nos bairros mais centrais com expansão na periferia da região metropolitana; apesar disso o número de casos é maior devido ao aumento da população.

A Lagoa da Pampulha, apesar do encontro recente de $B$. tenagophila naturalmente infectada pelo $S$. mansoni, não parece ter a mesma importância de seus afluentes (nem a importância que tinha no passado) na transmissão da doença em Belo Horizonte.

$O$ transmissor mais importante da esquistossomose no Estado de Minas Gerais continua sendo a B. glabrata. Recentemente, entretanto, a B. tenagophila naturalmente infectada pelo $S$. mansoni vem sendo encontrada em algumas localidades, podendo assumir no futuro importância epidemiológica na transmissão da doença.

\section{REFERÊNCIAS BIBLIOGRÁFICAS}

1. Cançado JR. Contribuição ao estudo da esquistossomiase mansônica no Brasil. Dados relativos à sua distribuição no Estado de Minas Gerais. Revista Brasileira de Medicina 4:31-35, 1947.

2. Camargo S. Impacto do desenvolvimento na expansão da esquistossomose. Revista do Instituto de Medicina Tropical de São Paulo 22 (supl. 4): 117-119, 1980.

3. Carvalho OS, Guimarães CT, Massara CL, Bonesio JER. Situação atual da esquistossomose mansoni no Lago da Pampulha, Belo Horizonte, MG, Brasil. Revista de Saúde Pública de São Paulo 19:270-277, 1985.

4. Carvalho OS, Souza CP, Katz N. Primeiro encontro de Biomphalaria tenagophila (d'Orbigny, 1953) naturalmente infectada com Schistosoma mansoni, em Itajubá, sul do Estado de Minas Gerais, Brasil. Revista de Saúde Pública de São Paulo 19:88-91, 1985.

5. Cotta E, Milward de Andrade R. A esquistossomose mansoni em Belo Horizonte, MG (Brasil). Situação antiga e atual do problema. Revista Brasileira de Malariologia e Doenças Tropicais 19:571-606, 1967.

6. Davis N. The microscopical examination of 29.593 human livers from Central and Northern Brazil, with special reference to the occurrence of malaria and schistosomiasis. The American Journal of Hygiene 19:567$600,1934$.

7. Dias Pinto AMS, Bizotto Pinto CM, Ferreira HLM, Assis LFS, Rolla ME, Junqueira MV. Presença de Biomphalaria straminea naturalmente infectada pelo Schistosoma mansoni na represa Samambaia, divisa dos Municípios de Lagoa Santa e Pedro Leopoldo, MG, março 1981. Ciência e Cultura 36 (supl.):893, 1984.

8. Projeto Cirandão Embratel. Distribuição de caramujos hospedeiros de $S$. mansoni em MG, 1985.

9. Hoffman WA, Pons JA, Janer JL. The sedimentationconcentration method in schistosomiasis mansoni. The Puerto Rico Journal of Public Health and Tropical Medicine 9:283-291, 1934.

10. Katz N, Carvalho OS. Introdução recente da esquistossomose mansoni no sul do Estado de Minas Gerais, Brasil. Memórias do Instituto Oswaldo Cruz 78:281$284,1983$.

11. Katz N, Chaves A, Pellegrino J. A simple device for quantitative stool thick-smear technique in schistosomiasis mansoni. Revista do Instituto de Medicina Tropical de São Paulo 14:397-402, 1972.

12. Katz N, Motta E, Oliveira VB, Carvalho EF. Prevalência da esquistossomose em escolares no Estadode Minas Gerais. In: Resumos do XIV Congresso da Sociedade Brasileira de Medicina Tropical, João Pessoa, p. 102, 1978.

13. Lambertucci JR. Ensaio terapêutico com a oxamniquine oral na esquistossomose mansoni crônica. Tese de mestra do, Universidade Federal de Minas Gerais, Belo Horizonte, 1981.

14. Lambertucci JR, Pedroso ERP. Esquistossomose mansoni. In: Marra UD (ed.) Medicina Ambulatorial, 1? edição, Editora Guanabara Koogan SA, Rio de Janeiro, p. 255-262, 1982.

15. Lutz AO. Schistosomum mansoni e a schistosomose segundo observações feitas no Brasil. Memórias do Instituto Oswaldo Cruz 11:121-144, 1919. 
16. Madureira Pará. Schistosomose mansoni no Brasil. Ocorrência em figados de viscerotomia no periodo de 1937-1946. In: Resumos do VII Congresso Brasileiro de Higiene, São Paulo, p. 142, 1948.

17. Martins AV. Sobre a pesquisa dos ovos de $S$. mansoni pelo método de sedimentação-concentração. Brasil Médico 51:319-321, 1937.

18. Martins AV, Falcão AL. Distribuiçāo geográfica dos planorbideos e seus índices de infestação pelas cercárias de Schistoma mansoni no Município de Belo Horizonte. In: Resumos do XI Congresso Brasileiro de Higiene, Curitiba, p. 81, 1953.

19. Martins AV, Versiani W. Plano de combate a "schistossomose mansoni" em Belo Horizonte. O Hospital 15:197-206, 1939

20. Martins AV, Versiani W. Schistosomose mansoni em Belo Horizonte. Brasil Médico 52:471-472, 1938.

21. Meira JA. Esquistossomiase mansoni. Subsidio ao estudo de sua incidência e distribuição geográfica no Brasil. Arquivos da Faculdade de Higiene e Saúde Pública da USP 1:25-40. 1947.

22. Melo AL, Pereira LH. Sobre o encontro de Biomphalaria tenagophila naturalmente infectada com Schistosoma mansoni no Município de Jaboticatubas, Minas Gerais. In: Resumos do VII Congresso da Sociedade Brasileira de Parasitologia, Porto Alegre, p. 180, 1982.

23. Milward de Andrade R. Nota ecológica sobre o Lago da Pampulha (Belo Horizonte, MG), com especial referência aos planorbideos (Pulmonata, planorbidae). Revista Brasileira de Malariologia e Doenças Tropicais 21:59-116, 1969.

24. Milward de Andrade R. O problema da esquistossomose mansoni no lago artificial da Pampulha, Belo Horizonte, Minas Gerais, (Brasil). Revista Brasileira de Malariologia e Doenças Tropicais 10:653-674, 1959.

25. Milward de Andrade R. Primeiro encontro de B. tenagophila (D'Orbigny, 1835) no Lago da Pampulha, Belo Horizonte, MG. In: Resumos do XIV Congresso da Sociedade Brasileira para o Progresso da Ciência, São Paulo, p. 101. 1972.

26. Paraense WL. Fauna planorbídica do Brasil. In: Lacaz CS, Baruzzi GR, Siqueira Jr. W (Eds.) São Paulo,
Edgar Blucher, Editora Universidade de São Paulo, São Paulo, Cap. 10, 213-239, 1972.

27. Paraense WL. Planorbideos hospedeiros intermediários do Schistosoma mansoni. In: Cunha AS (ed.) Esquistossomose mansoni, 1: edição. Editora Universidade de São Paulo, São Paulo, p. 13-30, 1970.

28. Paulini E, Dias EF, Fiuza H. Contribuição à epidemiologia da esquistossomose em Belo Horizonte. Revista Brasileira de Malariologia e Doenças Tropicais 19:571606, 1967.

29. Pellon AB, Teixeira I. Distribuição geográfica da esquistossomose mansônica no Brasil. Divisão de Organização Sanitária, Rio de Janeiro, 1950.

30. Pellon AB, Teixeira I. O inquérito helmintológico escolar em cinco estados das regiōes Leste, Sul e CentroOeste. Divisão da Organização Sanitária, Rio de Janeiro, 1953.

31. Prado Júnior C. História econômica do Brasil. Editora Brasiliense, São Paulo, 1970.

32. Rey L. Parasitologia. Editora Guanabara Koogan SA, Rio de Janeiro, 1973.

33. Rodrigues da Silva J. Estudo clínico da esquistossomose mansoni. Tese de livre docência, Faculdade Nacional de Medicina, Rio de Janeiro, 1949.

34. Silva P. Contribuição para o estudo da schistosomiase na Bahia. Brasil Médico 22:281-283, 1908.

35. Souza CP, Pereira JP, Rodrigues MS. Atual distribuição geográfica dos moluscos hospedeiros intermediários do Schistosoma mansoni em Belo Horizonte, MG, Brasil. Memórias do Instituto Oswaldo Cruz 76:383-391, 1981.

36. Teixeira JM. A schistosomose mansônica na infância em Belo Horizonte. Tese de concurso, Universidade Federal de Minas Gerais, Belo Horizonte, 1920.

37. Versiani W, Martins AV, Pena Sobrinho O. Esquistossomose mansônica no Estado de Minas Gerais. Arquivos do Instituto Químico-Biológico do Estado de Minas Gerais 1:71-94, 1945.

38. Villela E. Contribuição ao estudo histopatológico do fígado na schistosomose mansoni humana. O Hospital 23:345-351, 1943. 